This item was submitted to Loughborough's Research Repository by the author.

Items in Figshare are protected by copyright, with all rights reserved, unless otherwise indicated.

\title{
Going too far: complaining, escalating and disaffiliation
}

PLEASE CITE THE PUBLISHED VERSION

http://dx.doi.org/10.1016/j.pragma.2008.09.046

PUBLISHER

(c) Elsevier

VERSION

AM (Accepted Manuscript)

LICENCE

CC BY-NC-ND 4.0

REPOSITORY RECORD

Drew, Paul, and Traci Walker. 2019. "Going Too Far: Complaining, Escalating and Disaffiliation”. figshare. https://hdl.handle.net/2134/13230. 
This item was submitted to Loughborough's Institutional Repository (https://dspace.lboro.ac.uk/) by the author and is made available under the following Creative Commons Licence conditions.

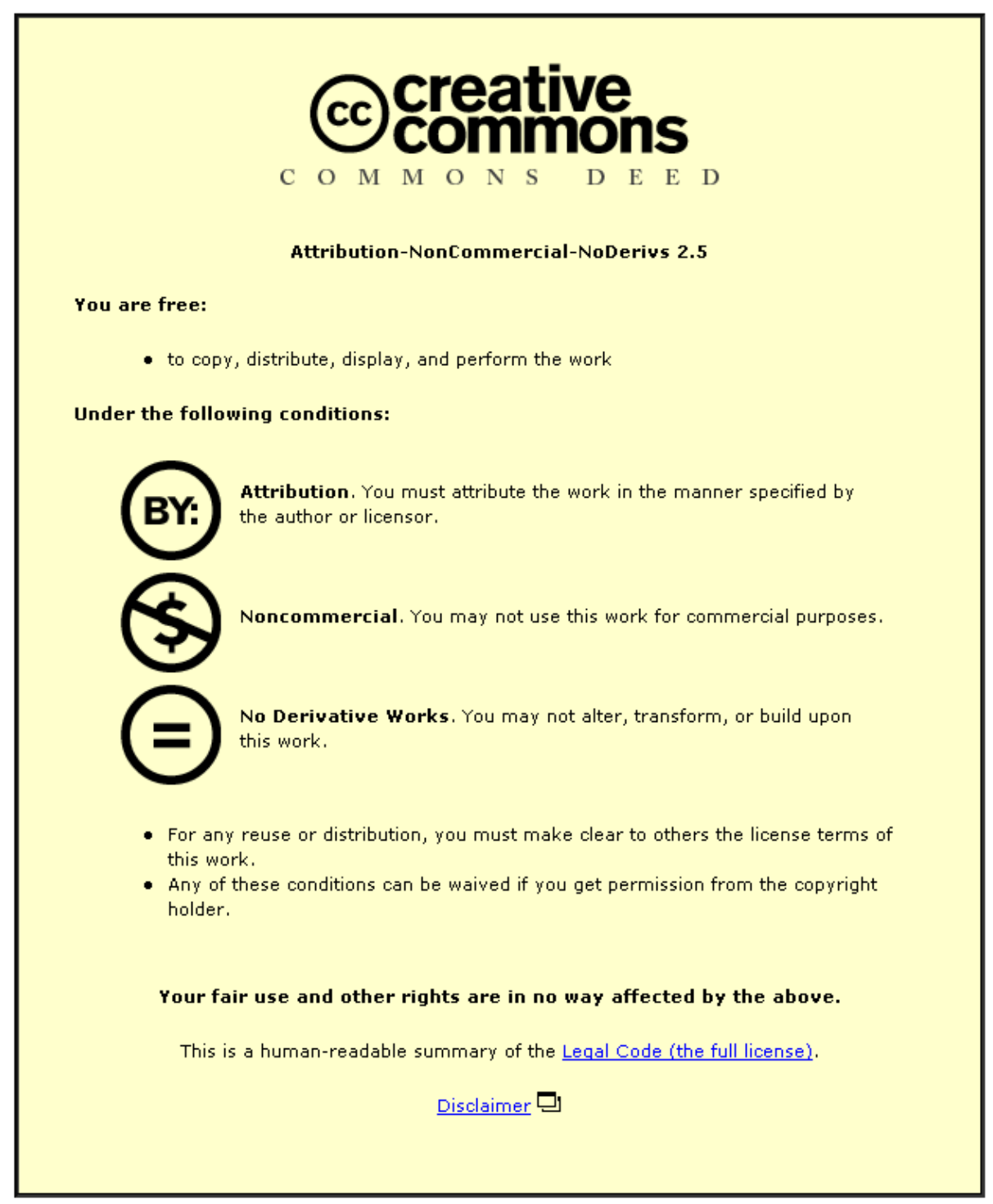

For the full text of this licence, please go to: http://creativecommons.org/licenses/by-nc-nd/2.5/ 


\section{Going too far: complaining, escalating and disaffiliation}

Paul Drew and Traci Curl

wpd1@york.ac.uk and tsc3@york.ac.uk

University of York, UK

Revised September 2007

For publication in a special issue on complaining in the Journal of Pragmatics, to be edited by Trine Heinemann and Veronique Traverso 


\begin{abstract}
$\underline{\text { Abstract }}$
This report, arising from a study of affiliation and disaffiliation in interaction, addresses an apparently 'anomalous' finding in relation to complaint sequences in conversation. In some of the cases we collected in which one speaker was complaining on behalf of the other (their coparticipant), taking her side in some matter, the one on whose behalf the other was complaining did not affiliate with the complaint. Instead they resisted the complaint (again, one made on their behalf) and demurred to 'go so far'. This finding is anomalous in the sense that if A is complaining on behalf of $\mathrm{B}$, in respect of some harm done to $\mathrm{B}$, then it might be expected that $\mathrm{B}$ would go along with the complaint, and affiliate with A. To account for how it might come about that B demurs from 'going as far as' A, we explore how complaints are frequently introduced in conversation. We show that complaints may emerge through a progression in which 'the complainant' does not initially go on record with a complaint, but instead secures the other's participation in co-constructing the complaint. Hence the 'complaint recipient' may be the first to make the complaint explicit, in a sequence of escalating affiliation. In the 'anomalous' cases, it appears that this escalation goes too far for the putative complainant (B).
\end{abstract}




\section{Going too far: complaining, escalating and disaffiliation}

\section{$\underline{\text { Introduction }}$}

In research we have been conducting into affiliation and disaffiliation in interaction, ${ }^{\mathrm{i}}$ we have been finding a recurrent but surprising phenomenon. In cases in which someone complains on the other's behalf, it commonly happens that the one on whose behalf the complaint is being made does not support or otherwise affiliate with the complaint. Instead they disaffiliate. What seems to us surprising, of course, is that when one complains on the other's behalf, she is after all affiliating with the other about some trouble or mistreatment she - the other - has experienced. We might expect, therefore, that the other would align with her co-participant, supporting the complaint being made on her behalf. But instead she declines to join (any further) with the complaint, and thereby disaffiliates from her co-participant's/'supporter's' position. What we are finding when this occurs is that it seems the 'recipient' has gone too far in escalating the complaint to a point beyond which the 'complainant' is comfortable. This paper is a report of that phenomenon, of the escalation of complaints about someone's mistreatment or misfortune, to a point at which that person pulls back and disaffiliates from the complaint the other is making on their behalf.

In order to show how it is that a recipient can take up a complaint on the other's behalf, and escalate it to a point where the other will not go, it is necessary first to outline how complaint sequences develop through the ways recipients affiliate with complainants, generally by collaborating in the complaining - indeed collaboratively co-constructing the complaint. We will then show that in doing so, recipients can end up having taken the complaining too far, formulating the complaint in way with which the 'complainant' does not agree. 


\section{Affiliation through collaborating in complaining}

The research literature has tended to treat a complaint as the first part in an adjacency pair, pairs of actions in which if one speaker does (or more properly, if a speaker's turn can be heard or recognized as doing) an initial action of a certain type, then the other (ie. the recipient) is expected to respond with an action paired with that first (type of) action. So a question should be answered, a greeting returned, a request should be granted or rejected, an invitation accepted or declined and so on. ${ }^{\text {ii }}$ Likewise, complaint sequences have been understood in terms of an initial action, the complaint, making relevant a specific type of paired action, one which either affiliates or disaffiliates with the complaint - the positive, affiliative response being 'preferred' over negative or disaffiliative responses, which are dispreferred (examples in the literature of complaint sequences treated as adjacency pairs include Dersley and Wootton 2000, Drew 1998, Pomerantz 1984:63 and Schegloff 1988:122). An example which might seem to illustrate the character of complaints as initiating adjacency pairs is the following, from a telephone conversation between two women, one of whom (Robbie) has recently started teaching at a school at which Lesley has taught in the past.

\#1 [Holt M88:1:5:3]

1 Rob: $\quad$ I: find her I get t'the stä:ge w'r I: I: come out'v

$2 \quad$ staff room cz I feel like saying t'her .hhh (0.2) if

3 you don' w'nna p't anything int'teaching, th'n why don't

$4 \quad$ you get out.=

5 Les: $\quad=$ That's rị

6 Rob: [Did you f- (.) Di[d you (feel the]sam[e)

7 Les: $\quad[\mathrm{Y}$ e : $\mathrm{s}$. ]Yes[she's

$8 \quad$ just ticking over issn't sh[e.

9 Rob: [Oh:: it's ridicu[lous.

10 Les: [Yẹ:s:.=

11 Rob: =I[really feel very](

12 Les: [W e 11 it's ni]ce to have this cha:t['n know that= 
13 Rob:

14 Les: $\quad$ =you feel the same $\cdot$ hhhh
$[\mathrm{Oh} !$

There is plainly an adjacency-like relationship between Robbie’s complaint in lines 1-4 and Lesley’s affiliative responses, which fit well with the timing, shape and design of preferred responses. In response to Robbie’s complaint about her colleague’s behaviour (not putting anything into teaching), Lesley affiliates, firstly by agreeing (line 5), then by producing another version of Robbie’s complaint that she doesn’t put anything into teaching, which Lesley characterizes as just ticking over (lines 7/8). ${ }^{\text {iii }}$ They are plainly aligned in their assessment or view of Robbie’s colleague (Lesley's ex-colleague), evident both in their affiliations with one another and Lesley’s summary that you feel the same (lines 12-14).

However, it would be misleading to view this excerpt in terms only of the adjacent and paired relation between the complaint and the responses to them, and to separate this 'pair' of actions from the context of the sequence(s) which preceded them. Although Robbie's complaint can be regarded as an 'initial' action in $a$ pair, it is by no means the initial action in the complaint sequence in which it occurred. Moreover, the recipient’s (Lesley’s) response cannot be understood simply with respect to the immediate prior action. This is because Robbie's complaint is really only one in a series of turns in which they have been collaboratively telling about, and complaining about, Robbie’s colleagues.

Although ‘preference organization’ is a way of conceptualizing the different ways in which affiliative and disaffiliative response turns are constructed, in terms of their timing (preferred responses tend to be done without delay, whilst dispreferred responses are frequently delayed) and structural design properties, 'preference organization' refers also to the ways in which actions are managed in such a way as to promote the likelihood of obtaining preferred or 
positive responses. The difference is this; 'preference', applied to the construction of responses, focuses on the linguistic resources which recipients use to design their turns so as to affiliate, or not, with the action in the prior turn. But 'preference' applied to sequence management refers instead to the work which (first) speakers - here complainants - may do in leading up to and preparing for a projected action, to enhance its chances of success. In other words, what happens before a complaint is made (explicit) - what work, if any, a complainant does in preparing the ground for a possible complaint - is salient to securing, or attempting to secure, a recipient's affiliation.

This can be illustrated by considering what preceded, and led up to, the complaint shown in \#1, which occurs towards the end of a sequence of talk which began when Lesley referred to something which happened when she was teaching at the school; she mentions one of the other teachers by name.

\begin{tabular}{|c|c|c|}
\hline \#2 & \multicolumn{2}{|c|}{ [Holt M88:1:5:2] } \\
\hline 1 & Rob: & Well it's quite a relief to hear you say that. $=\mathrm{c}[\mathrm{uz}$ \\
\hline 2 & Les: & [Yes I \\
\hline 3 & & found they got very high last term an' I kept saying to \\
\hline 4 & & Miss Pelch:: that I .hhhh e-were hers hi::gh? a:n:'she \\
\hline 5 & & wz saying no everything wz going along steadily'n.hh[hh \\
\hline 6 & Rob: & {$\left[\mathrm{W}^{\prime} \mathrm{l}\right.$} \\
\hline 7 & & $\mathrm{I}[$ (wonder) $]$ \\
\hline 8 & Les: & [mine were]terribly excited. f'some [reason. \\
\hline 9 & Rob: & [Ye::h. \\
\hline 10 & & $(0.3)$ \\
\hline $\begin{array}{l}11 \\
12\end{array}$ & Rob: & 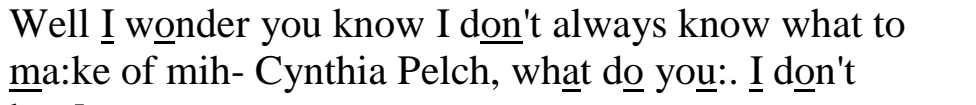 \\
\hline 13 & & kno $[: w$. \\
\hline $\begin{array}{l}14 \\
15 \\
16\end{array}$ & Les: & $\begin{array}{l}\text { [.hh No, I think she- (.) aa- well. b-di-Quite } \\
\text { honehhstly .hhh I think she c'n be ru:de. An', an' I } \\
\text { think Freddie Masters can too[:, }\end{array}$ \\
\hline $\begin{array}{l}17 \\
18 \\
19\end{array}$ & Rob: & $\begin{array}{l}{\left[{ }^{\circ} \mathrm{Oh}:, I_{\text {kno:w. }}{ }^{\circ} \text { I mean I }\right.} \\
\text { haven't run up against them but I do: }{ }^{\prime} \text { 't find th'm } \\
\text { overhelpful. }\end{array}$ \\
\hline 20 & Les: & $=$. hhh No, (.) nuh- (.) no help at all fr'm Freddie \\
\hline
\end{tabular}


Masters an a:n' sometimes I've had f- almost to be:g. .h[hh[for things.

Rob: $\quad$ [Ye[s

Rob: $\quad$ W'l I had a quick word with uh::m what ${ }^{\circ} \mathrm{m}$ oh ${ }^{\circ}$ Netty Daltry. She's nice cuz I'm helping her- well. .hhh today wz the eh:m she wz practicing in the ha:ll with the three classe[s.

Les:

[.h Ye[s.

Rob:

[An' Freddie Masters said well she wz doing stock taki:ng an:d and em (0.4) she wouldn't

Les: $\quad=$ Yes.=

Rob: $\quad$ =So I went in'n obviously no:b'dy wz prepared to: help. .hh Cynthia Pelch disappea:red 'n ( )- uh ( ) Rob: $\quad$ hh I said well blow this I:'m g'nna check up where she is...

Robbie has taken over teaching a primary (elementary) school class that previously Lesley has taught. Just before this extract begins, Robbie has remarked on the difficulty she's having keeping order in the classroom, to which Lesley responded that she also found they got very high towards the end of last term. She attributes this to Comic Relief and the upcoming Easter break; ${ }^{\text {iv }}$ and, now that Robbie is teaching them, to having the school concert looming (data not shown). At the start of this fragment, Lesley repeats the description of the children being very high last term (line 3), and reports comparing notes with a colleague, Miss Pelch, about her class (lines 36 and 8). There may be a critical thrust in her reporting that she kept saying to Miss Pelch...were hers high?, and the insouciance of Miss Pelch’s reply (line 5) (the point being that if Lesley’s class were so excitable, were Miss Pelch’s really not, or was she oblivious to them, not admitting it, or what?). But if there is a critical implication in that reference to Miss Pelch, it becomes a parenthetical remark when Lesley brings it to a close by restating that mine were terribly excited, thereby returning to the original matter of Robbie's difficulty in keeping the children under control (line 8). 
Robbie resists this return to the children's excitability, and works to topicalize instead Miss Pelch. She first attempts to do so immediately after Lesley’s remark about Miss Pelch, W'l I wonder (lines 6-7), but abandons that when she finds herself speaking in overlap with Lesley’s closure and return to the difficulty with the children. Robbie's response to this, Yeh in line 9, is minimal; after which she resumes by repeating what she had begun in line 6 , in response to Lesley’s reference to Miss Pelch. That is, she starts again with Well I wonder; the character of this turn as 'starting again', to pull back to the matter of Miss Pelch and elide (hence resist) Lesley's return to the excitability of the children, is particularly evident in her repeating the turninitial well, which is almost always omitted in post-overlap self-retrievals or when (partially) repeating in response to other repair initiation. Resuming her turn in this way, by repeating Well (more fully), underlines that Robbie is now specifically not aligning with Lesley’s move back to the children's excitability. She (Robbie) is taking the talk in another direction.

All of which is to say that Robbie works to make a topic of something that Lesley remarked on only parenthetically, in referring to Miss Pelch. In topicalizing this reference, Robbie first conveys an equivocal stance towards this colleague (now given her first and last name, line 12), an equivocality expressed idiomatically as I don't always know what to make of..... Robbie then forms the beginning of an enquiry, What do you (line 12), which she leaves incomplete, cutting back instead to her equivocation (I don't know, lines 12-13). In this way she has sought, but not quite asked directly for, Lesley’s view about Cynthia Pelch; she has hinted at, but not stated outright, her own critical view. Robbie is evidently guiding the conversation to the topic of Miss Pelch, has something critical to say about her, but is approaching the matter cautiously. 
Lesley’s response to Robbie’s tentative, almost-an-enquiry, is pivotal in encouraging the complaint which Robbie proceeds to make. Lesley's overt criticism that Cynthia Pelch can be rude, adding that another teacher can also be rude (lines 14-16), leads to a lengthy complaint sequence in which Robbie first agrees with or confirms Lesley’s assessment (line 17), then embarks on an account in which both Cynthia Pelch and Freddie Masters feature in her complaint about how little they are prepared to help. Even here, in moving closer towards the complaint story, Robbie is cautious in the way she expresses their unhelpfulness (I don't find them overhelpful, lines 18-19). Only when Lesley responds with a stronger formulation of that criticism (eg. no help at all, line 20) does Robbie then embark fully on a narrative in which she complains about how little her colleagues are prepared to help. And again she only minimally acknowledges Lesley's account of her difficulty with Freddie Masters (Robbie’s Yes in line 23, in response to Lesley's account in lines 20-22), before beginning a disjunctively (Well) prefaced narrative account of her own difficulties. So as before, while resisting the particular direction of her recipient's prior turns, Robbie exploits them as resources to launch her complaint.

All of this will culminate in Robbie's complaint in \#1, that Freddie Masters doesn't want to put anything into teaching. When a little later in her narrative (24 lines omitted) Robbie continues with another formulation of her complaint (you go out of your way to help somebody and you find you're doing it all, \#3 lines 1 and 3), Lesley agrees and elaborates the complaint about Freddie Masters (starting line 4).

\#3 [Holt M88:1:5:3-4]

1 Rob: $\quad$ Ye:s. you [know you'd go]out your way to help someb'dy=

2 Les: [ $\quad$ Y e : s.]

3 Rob: $\quad=$ 'n 'n you find you're doing it a $[$ [ll.

4 Les: $\quad$ [.hhhhh That's right.

5 An' and also: I found th't I got no:: u-help from the

$6 \quad$ assistants, well: they were willing to help but .hhhh 
9 Rob:

10 Les:

11

Rob:

Les:

Rob:

Rob:

Les:

Rob:

eh as soon as any chance of anybody, grabbing 'n assista[nt,

[Yes

.hhhh eh:m: n-you know who grabbed them::.

(0.3)

u- Frih- uh:: Freddie Masters.

Ye:s:.

I: find her I get t'the stạ:ge w'r I: I: come out'v staff room cz I feel like saying t'her .hhh (0.2) if you don' w'nna p't anything int'teaching, th'n why dn't you get out.=

Les: $\quad=$ That's rị:gh[t,

jụst ticking over isn't sh[e.

[Did you f- (.) Di[d you (feel the]sam[e)

[ Y $\underline{\mathrm{e}}: \mathrm{s}.] \mathrm{Yes}[\mathrm{she's}$

[Oh:: it's ridiculous.

Robbie and Lesley are by now working collaboratively to co-produce or co-construct (Ochs et al.1995) the complaints, most clearly where in line 10 Lesley asks and you know who grabbed them, to which Robbie answers Freddie Masters (line 12). It is after this that Robbie summarises her complaint that Freddie Masters doesn't want to put anything into teaching and therefore should get out (lines 14-17).

So that when Robbie arrives at her most explicitly and strongly critical expression about her colleague, she does so after an extended sequence which she began cautiously, with an equivocal indication of criticism about Cynthia Pelch (this develops Mandelbaum's account of how "..complaining can be carried out in such a way as to make available to a co-participant the opportunity to join in with the complaint”: Mandelbaum 1991/1992: 104). This generated a series of collaborative moves in which Lesley first made a more explicit criticism, and then each has collaboratively developed and elaborated complaints about colleagues at the school being unhelpful, culminating in Robbie's complaint about Freddie Masters - at which point, therefore, 
she has every reason to expect, indeed rely upon, Lesley’s agreement and affiliation, given Lesley’s collaboration in and co-construction of the complaint(s).

The complaint shown in \#1 (see also \#3) was not, therefore, a 'first' complaint. The complaint sequence shown in \#1, in which the recipient (Lesley) affiliates with Robbie's complaint, is the culmination of a complaint narrative in which Robbie first 'fixed' or topicalised a parenthetical reference by Lesley, which touched off Robbie’s narrative/complaint. Robbie moved into this complaining cautiously; by implying at least an equivocality about her colleague, and not-quite-directly-inquiring what Lesley thought, Robbie provides an opportunity for her recipient to indicate her view of the colleague's conduct, and subsequently to collaborate in complaining. The complainant does not launch straight into her complaint. Instead she topicalises the complainable matter in such a way as to leave it to her recipient to take it up by making the complainable more explicit, if she will (on the concept of 'complainable', in part relating to formulating prior utterances, see Sacks 1992:46-47 and 150-151, taken up by Schegloff 2005). Hence Robbie’s complaint emerges out of a narrative sequence in which she secures her recipient's overt criticism of her colleagues, and her recipient's collaboration in constructing the complaint. The practice or device the complainant used was to hint at, or adumbrate, a criticism, eliciting her recipient's views or judgement before committing herself to complaining explicitly. So Robbie’s complaining is not located in or restricted to a single turn; instead it was managed through a narrative of events, at several points during which complaints are formulated. Robbie's complaint in \#1, that her colleague doesn't want to put anything into teaching, is only the summary end point of that complaining sequence.

Although occasionally complaints may be one-off initial actions, without (apparently) any preceding conversational context, generally complaints are not made ‘out of the blue’. Given 
the usual limitations of space, we have been able to show only a single case here: however, in the great majority of our sample of 80 complaint sequences, complaints were adumbrated in and emerged from the prior talk, in which a 'misfortune' (mistake, mischance, misdeed, misdemeanour etc.) was transformed over the sequence from being a 'complainable' matter into an overt complaint. It appears, then, that systematically complainings are managed sequentially, beginning with more incipiently complainable matters, through to an explicit complaint, in ways which can secure the complaint-'recipient's' affiliation (to recruit the recipient to the complainant's position) before a complaint is made explicitly - though the particulars of the sequential emergence of a complaint, and the particular practices involved, differ in different

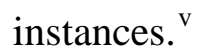

As a consequence, generally complaints are not singular actions; they are done in series, in complaining sequences in which co-participants both/all may play a part in formulating complaints. In tracking the sequence leading up to Robbie’s complaint in \#1, we should highlight three features, in particular, which are characteristic of complaint sequences in conversation that is, sequences in which co-participants are complaining about some non-present third parties (and not about one another).

- The one who emerges as the complainant, here Robbie, does not initiate the sequence with an explicit, on-the-record complaint. Instead she moves into the sequence cautiously, through topicalizing something complainable, and securing her coparticipant's participation in constructing the complaint.

- The participants collaboratively co-construct the complaining, each formulating versions of the complaint, and adding to the other's versions. Indeed, the identities 'complainant' and 'complaint recipient' are no longer stable or fixed; although in some overall sense 
Robbie seems to be the complainant and Lesley the complaint recipient, at some local points in the sequence these identities are reversed.

- In co-constructing the complaining, and adding to or elaborating a formulation by the other, there is an escalation in the complaining. For instance we saw how the 'recipient', Lesley, was the first to make explicit what Robbie had left only implicit; and then went further than Robbie in some of her formulations.

These, then, are some of the systematic features of the ways in which complaints sequences emerge and develop, from the allusion to or mentioning of a complainable matter (I don't always know what to make of.....), escalating into explicit formulations of wrongdoing and shortcomings in another's conduct - in part through the 'recipient' affiliating with the complainant by collaborating in the complaining. These features, or properties of complaint sequences, help us to understand how in some cases the one on whose behalf a complaint is formulated comes to disaffiliate with her co-participant.

Escalating to a place where the initial 'complainant' does not want to go: complainant disaffiliation

In the pattern of co-complaining that is characteristic of affiliation in complaint sequences, a recipient joins with the one who initiated the complaining (albeit implicitly) and adds to the account of the complainee's misconduct. The 'recipient' elaborates or makes more explicit the complainable matter, or takes up telling about their similar experience of the complainee's behaviour. This can have two interrelated consequences. First, the recipient may take up the complaining, either on their own behalf, or on behalf of the original complainant. The other consequence is that in making the complaint more explicit, and adding to and elaborating 
the complaint, there is a certain escalation in the complaining. The first of these consequences is illustrated in the following example, in which Lesley has told Mum, near the start of the call, that their telephone line was cut off by the telephone company (British Telecom), because she and her husband had omitted to pay the 'phone bill, explaining that they always wait for the final demand, and on this occasion when they received that, they forgot.

\begin{tabular}{|c|c|c|}
\hline \#4 & & [H:X(C)85:1:1:6:1-2] \\
\hline 1 & Les: & An' so: uh when I picked the phone up on Thu:rsda:y \\
\hline 2 & & it wz completely dead. \\
\hline 3 & & (.) \\
\hline 4 & Mum: & Oh: they make you pay f'r putting it on again too.:. \\
\hline 5 & Les: & Yes well we sent the money straight awa $\underline{a}$ y \\
\hline 6 & & $(0.4)$ \\
\hline 7 & Les: & .p \\
\hline 8 & & $(0.2)$ \\
\hline 9 & Les: & And we had it uh:m: back on on Fridee afternoon \\
\hline 10 & Mum: & hmhh: \\
\hline 11 & Les: & But apparently they cut w- fi:ve people off in \\
\hline 12 & Les: & Galhampto[n: on[: Thursday- \\
\hline 13 & Mum: & {$[($ )![( $\quad$ ) } \\
\hline 14 & Mum: & Oh: lo:ve. \\
\hline 15 & & $(0.4)$ \\
\hline 16 & Mum: & That's a nuisance isn't it. \\
\hline 17 & Les: & $\mathrm{Ye}[\mathrm{s}$. \\
\hline $\begin{array}{l}18 \\
19\end{array}$ & Mum: & $\begin{array}{l}\text { [They're getting terrible. } \\
(0.3)\end{array}$ \\
\hline 20 & Les: & We:l[1- I s a i d $]$ \\
\hline $\begin{array}{l}21 \\
22\end{array}$ & Mum: & $(0.2)^{\text {[I mean look what] }}$ \\
\hline 23 & Les: & I said to them. this is British Telecom for you $(\mathrm{h})=$ \\
\hline 24 & Mum: & 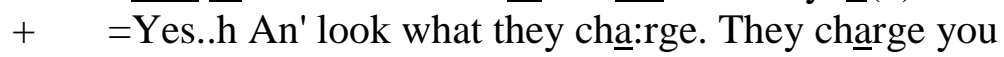 \\
\hline 25 & & .h three pounds (just t'have) this wretched old thing \\
\hline 26 & & in your hous:se \\
\hline 27 & & $(0.5)$ \\
\hline 28 & Les: & Yes.= \\
\hline 29 & Mum: & $=$ An' then all the an' then a:ll that (0.2) money- \\
\hline 30 & & (0.3) sev'nteen pounds something on top'v that. \\
\hline 31 & Les: & Yes:. \\
\hline 32 & Mum: & for se:rvice. \\
\hline 33 & & (.) \\
\hline 34 & Les: & hh $\underline{\text { Ye:s:. }}$ \\
\hline
\end{tabular}


35 Mum: + hI've never had any service from them. Never.

36 Les: $\quad$ No: $:$ No:.

37 (.)

38 Les: $\quad$ Oh I haa (.) we ha:ve,...

In each of the marked turns, Mum makes more explicit a complainable matter concerning the telephone company's service. It may be noted that in doing so, Mum treats these matters as complainable in a way which Lesley herself does not. The closest that Lesley comes in this sequence to overtly complaining is in lines 20 and 24, I said to them this is British Telecom for you, which is a kind of generalised disaffection summary/completor. It is Mum, the putative recipient, who explicitly complains about the reconnection charge (line 4), that they're getting terrible (line 18) and the service charge added to the bill, for a service she hasn't received (lines 25-36). It seems that Lesley is treating the matter of being disconnected by the phone company as an unfortunate consequence of her own oversight (failure to pay the bill); whereas Mum turns this into a complainable matter about the phone company, initially on Lesley's behalf, and subsequently in her own right. It is evident in the opening lines that they are not aligned about whether this is to be a tale about a misfortune, or a complainable matter.

[From \#4 lines 1-9]

1 Les: $\quad$ An' so: uh when I picked the phone up on Thu:rsda:y

2 it wz completely dead.

3 (.)

4 Mum: $\quad+\quad$ Oh: they make you pay f'r putting it on again toㅁ:.

5 Les: $\quad$ Yes well we sent the money straight awä:y

$6 \quad(0.4)$

7 Les: $\quad$.p

$8 \quad(0.2)$

9 Les: $\quad$ And we had it uh:m: bạck on on Fridee afternoon 
When Mum formulates a complainable matter concerning the reconnection charge (line 4),

Lesley does not join with or share in the complaint; her response (lines 5 and 9) is a quite neutral report that minimises the problem (minimising the disturbance caused, insofar as their line was reconnected, 'back on', the next day).

Mum subsequently complains more overtly, moving away from Lesley’s problem to a more generalised complaining about British Telecom's charges and service.

[From \#4 lines 14-32]

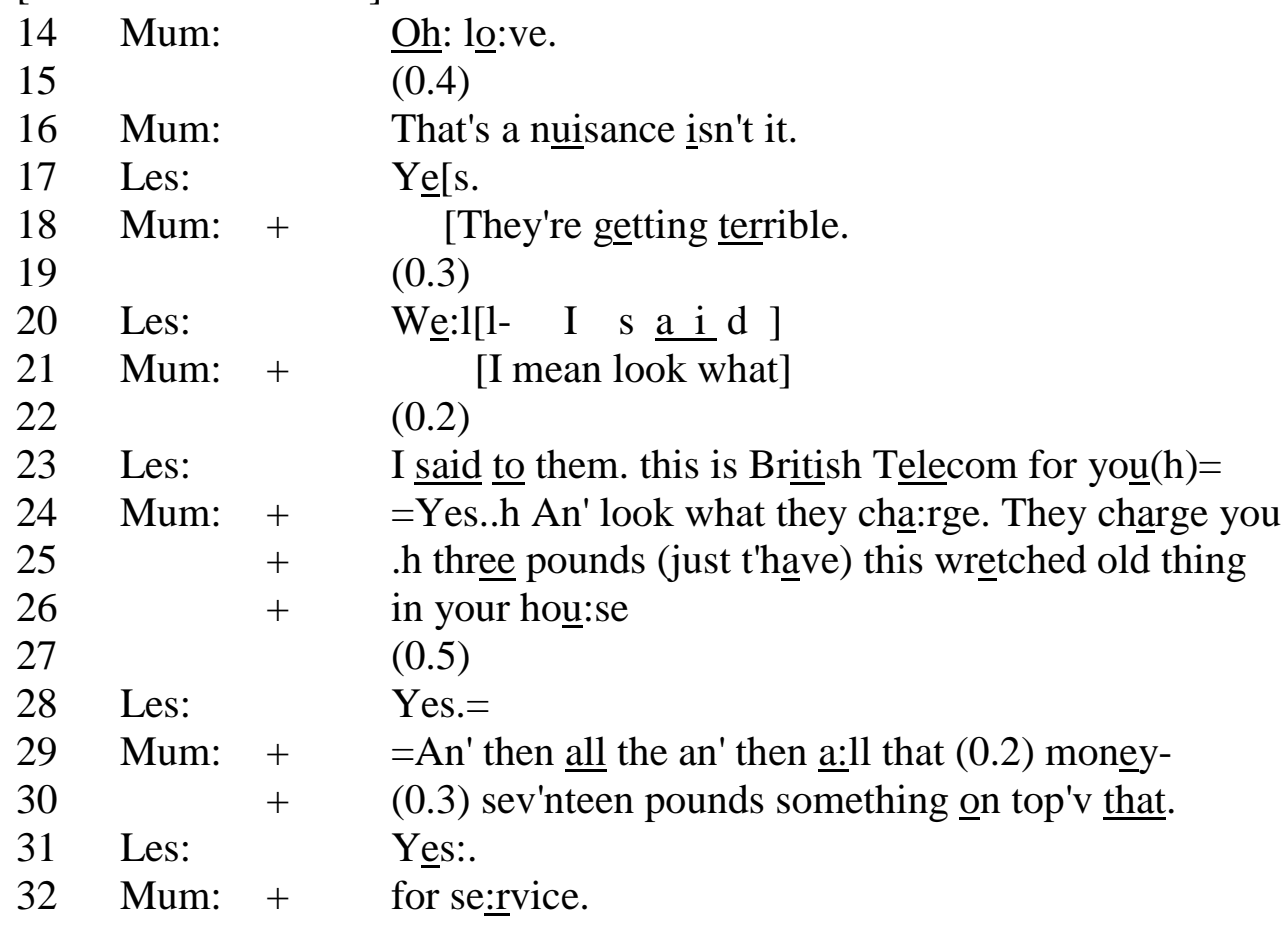

In this transition, and in what she adds in lines 24-32), Mum - who was initially the recipient of Lesley's account of their misfortune (being disconnected) - emerges as the one to complain most explicitly. Mum has treated Lesley as having reported a complainable matter. It is not at all clear that Lesley designed her report to be anything other than about a misfortune arising from her own oversight (forgetting to pay the bill). Although so when I picked the phone up on Thursday it was completely dead can be treated as a complainable matter - as indeed Mum does - there is 
no indication that Lesley told this as a complainable matter. Hence when Mum affiliates with Lesley by consolidating that into, explicitly, a complaint, she goes further than Lesley had done. She is now taking up the complaint on Lesley's behalf, as it were - in such a way that Lesley is now the recipient. It should be noted that Mum constructs her turn in line 12, in which she complains specifically about what they charge, as a response to Lesley's rather generalised complainable summary in line 11, through the turn-initial and prefaratory Yes an' in line 12: however she is in fact restarting her turn in line 8, look what..., in which she was about to launch this next complaint, but cuts off when she finds herself in overlap with Lesley. As the sequence has developed, Lesley’s misfortune has been transformed into Mum’s complaint on Lesley’s behalf, so that it has now become a matter of Lesley affiliating with Mum’s complaints; which she does without conviction or enthusiasm, in line 37 of \#4. ${ }^{\mathrm{vi}}$

This illustrates the way in which a recipient may take up the matter which the other has been telling about, and affiliate with her (the teller) by consolidating the complainable matter into an explicit complaint. She does so by adding to or elaborating the complaining, thereby taking the initiative in the complaint sequence - here, to the point where she (Mum) has become the complainant. In doing so, moreover, she contributes to (takes the lead in) escalating the complaint; indeed there's some evidence that she escalates it to a point going beyond what Lesley was originally reporting as the problem.

The escalation of a complaining through the collaborative participation of the recipient is further and quite dramatically illustrated in the following fragment from a long call between a brother and sister, both adults living far apart, in which the sister is complaining again (ie. she has done so at several points during the call prior to this) about their parents (they in line 1 and on). 


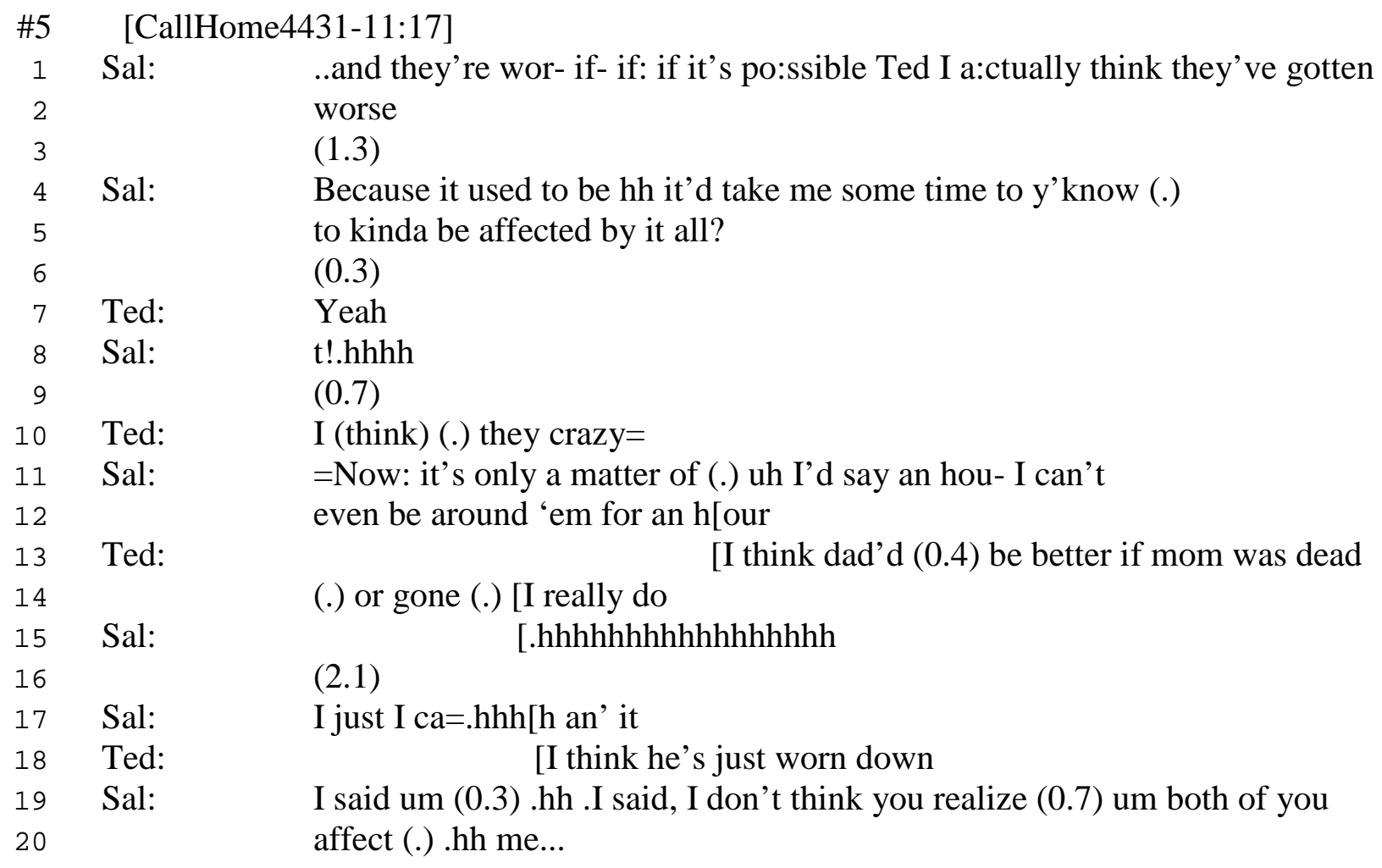

The escalation evident in this extract occurs in part through Sal's upgraded versions, in lines 1-2 when she cuts off what was going to be they're worse and strengthens it to if it's possible...I actually think they've gotten worse; and again in lines 11-12, when she begins to say what was probably going to be it's only a matter of an hour, but cuts off and replaces with the stronger version I can't even be around 'em an hour. But it is particularly apparent when Ted joins in with I think dad'd be better if mom was dead or gone (lines 13-14). There is a prolonged silence following this escalation (line 16), following which - without responding directly to Ted's prior turn - Sal resumes her account in line 17 with what seems to be a partial repeat and elaboration of her prior turn (I can't even be around 'em for an hour in lines 11-12, then I just ca- in line 17). Sal thereby elides Ted's escalation (see also his recycling that in line 18, to which again she does not respond in line 19-20), suggesting her resistance to his having gone that far. 
It is beginning to be evident in these cases that 'recipients' affiliate with tellers by making explicit a complaint which was only adumbrated in what the other has told consolidating as a complaint what the teller had described as a trouble or misfortune; and by collaborating with the teller in co-constructing the complaint. Either way, it appears that the recipient 'goes too far' in their co-complaining. Through their affiliative collaboration in the complaining, erstwhile recipients contribute to escalating the complaint to a place where the other will not go. The other does not affiliate with, and thereby pulls back from, a position to which the recipient has escalated them, displaying that they 'do not feel the same way’ as recipient; the co-participants have become misaligned.

This happens in the following extract, just before which Lesley has asked Mum what she’s been doing today (it’s one of their regular Sunday evening telephone calls); ${ }^{\text {vii }}$ Mum replied Not a lot, just been to church today that's about all, from which Lesley infers You haven't had your friend to tea (line 1).

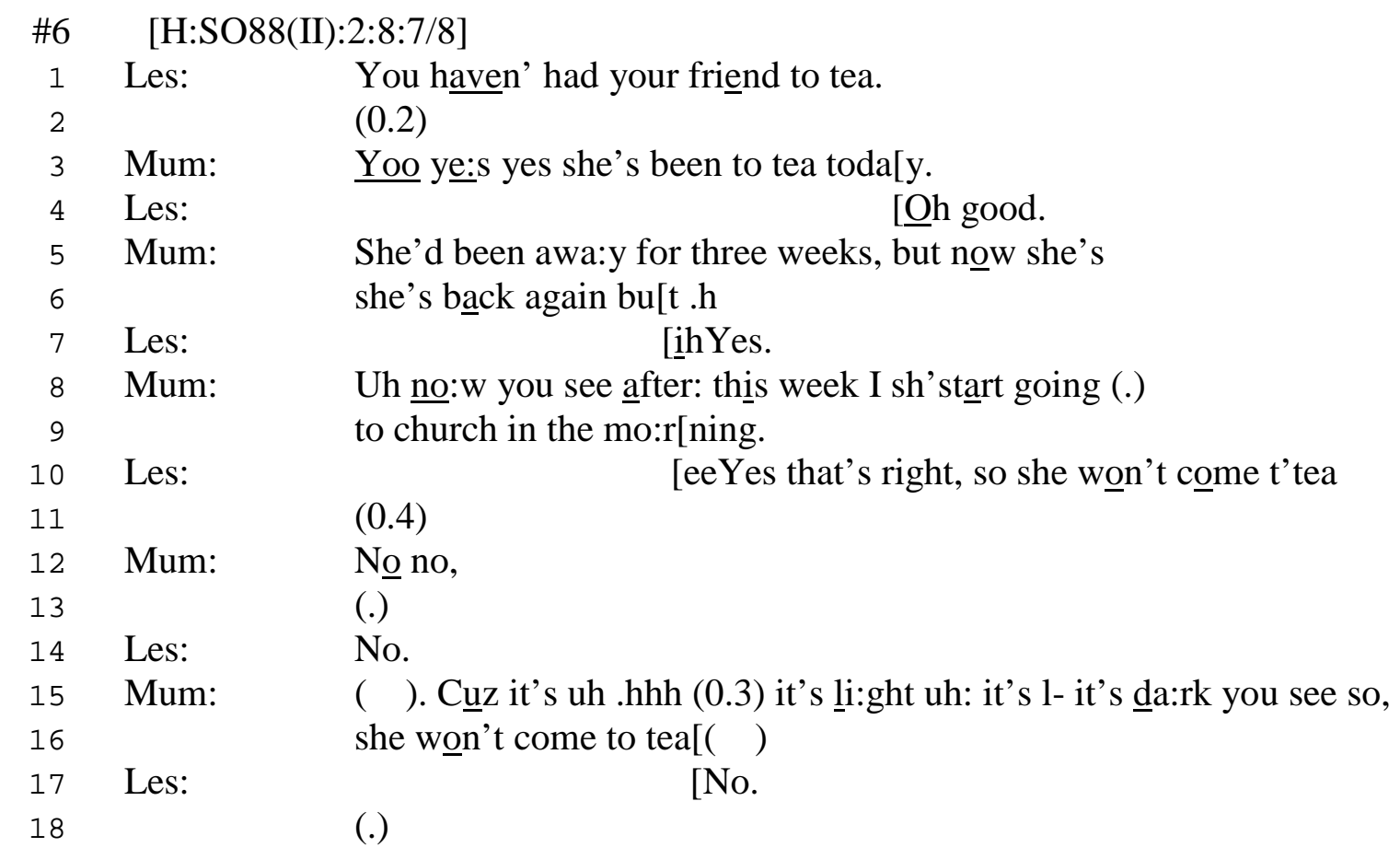




\begin{tabular}{|c|c|c|}
\hline 19 & Mum: & Occassionally probably ${ }^{\circ} \mathrm{hm}:^{\circ}$ \\
\hline 20 & Les: & $\mathrm{Hm}$ \\
\hline 21 & & $(0.8)$ \\
\hline 22 & Mum: & Yes c'z she gets someone'take her home you see so \\
\hline $\begin{array}{l}23 \\
24\end{array}$ & & $\begin{array}{l}\text { (U.2) sne s alrignt } \\
\text { Oh sh- so she still comes t'chur.rch does she in the }\end{array}$ \\
\hline 24 & Les: & $\begin{array}{l}\text { On sh- so she still comes t' chu:rch does she in the } \\
\text { eve[nings? }\end{array}$ \\
\hline 26 & Mum: & [Oh yes c’z someone takes her h-all the way ho:me. \\
\hline 27 & Les: & .hhh hoh:. \\
\hline 28 & Mum: & ${ }^{\circ}$ So:, hhm $\underline{\text { : }, ~ h[m ~ s o ~ s h e ' s ~ a l r i g h t, ~}$ \\
\hline 29 & Les: & [.hh \\
\hline 30 & Les: & That's a bit'v'n imposition though isn'it? \\
\hline 31 & & $(0.3)$ \\
\hline 32 & Mum: & What dear? \\
\hline 33 & Les: & .hhhh \\
\hline 34 & & (.) \\
\hline 35 & Mum: & $\underline{\text { Well }}$ they don't seem t'mind, ${ }^{\circ} \underline{h m}^{\circ}$ \\
\hline 36 & & (.) \\
\hline 37 & Les: & .tch uh Don' take you home though do they. \\
\hline 38 & Mum: & eh heh huh \\
\hline 39 & & (.) \\
\hline 40 & Mum: & We-:Ill? \\
\hline 41 & Les: & .t.hhhhh \\
\hline 42 & Mum: & They would if I: p-if I:-: press[ed for it? \\
\hline 43 & Les: & [.hhhhhhhhhh \\
\hline 44 & Les: & Ye्:s. \\
\hline 45 & Mum: & B’t I do:n’t. Huh hm:. \\
\hline 46 & & $(0.4)$ \\
\hline 47 & Les: & hAh $:$ : \\
\hline 48 & Mum: & Actually the pers'n 't use t'take me: ... \\
\hline
\end{tabular}

Evidently, from Lesley’s enquiry in line 1 and Mum’s account of her friend having been away (lines 5-6), her friend habitually comes to her for tea after the early evening service at their church. Mum explains (lines 8-17) that her friend will not continue coming to tea, because Mum will start going to church for the morning service - this because the clocks will be put forward one hour to GMT, and so it will be dark when the early evening service finishes. Mum then adds that her friend gets someone to take her home you see so she's alright, which Lesley takes to imply that her friend will continue to come to church in the evenings (lines 23-26). 
There is, then, a sequence in which Mum reports that her friend will be taken home (lines 23-24). Lesley makes explicit an inference from that, that her friend will continue going to church in the evenings (lines 25-26); Mum confirms that (lines 27-29); in response to which Lesley formulates Mum's friend getting a lift as a complainable matter, That's a bit of an imposition though isn't it? (line 31).

In doing so, Lesley may be orienting to four aspects of Mum’s report and confirmation (that her friend will continue going in the evenings) that are tinged with an incipiently complaining character. First, she says specifically that she gets someone to take her home, where gets casts her friend as close to something like requiring a service of someone. Second, Mum completes that report with the expression so she's alright (line 24) which, though a possibly 'innocent' completor, has an almost idiomatic meaning as a complaint, about someone looking after herself and not caring about others. Moreover, third, Mum repeats just this formulation, also as a completor, now of her confirmation (line 29), a reprise which might lend that expression additional prominence. Fourth, when she confirms Lesley’s inference, Mum adds specifically "all the way home”.

Each of these elements is balanced between neutral/innocent, and complaint-implicative. She gets someone to take her home may no more ‘intentionally’ imply having others perform a service, than he had his father shot by the Nazis - said about a famous Jewish publisher whose family perished during the war - could be taken to mean that the person in question arranged for his father to be killed. ${ }^{\text {vii }}$ These have become commonplace grammatical constructions, in place of alternative constructions in which the person being spoken about is not in subject position. So she's alright may, as already suggested, be designed as a 'literal' completor of the account of her friend being taken care of. And all the way home may be added in the service of explaining why 
her friend won't be coming to tea (ie. not able to stop by on her way), rather than tinged with envy about her friend being looked after. In each of these ways, then, Mum’s report and confirmation are poised between a neutral or 'innocent' account of the circumstances, and one which adumbrates something complainable. If there is anything that is complainable, it is only incipient in Mum's report and confirmation.

So Lesley's complainable formulation in line 31 brings to the surface what may have lain embedded in what Mum said - or at least, which is to be found embedded in what she said.

[From \#6]

30 Les: $\quad$ That's a bit'v'n imposition though isn'it?

$31 \quad(0.3)$

32 Mum: What dear?

33 Les: $\quad$.hhhh

$34 \quad$ (.)

35 Mum: $\quad$ Well they don't seem t'mind, ${ }^{\circ} \underline{\underline{m}}^{\circ}$

Mum's response to this (more) overt formulation of a complaint is not fully affiliative. It is delayed (line 32), after which Mum initiates repair (frequently associated with disaffiliation and disagreement; see Drew 1997) (line 33); and before any repair by Lesley, Mum constructs a turn/position in which she does not quite go along with Lesley (in her well-prefaced turn, marked as disjunctive, in line 35; on well as a delaying and hence disjunctive device, see Sacks 1987). In they don't seem to mind (line 35), Mum does not contest Lesley's proposal that it is an imposition, but qualifies the complainability of that imposition - although they don't seem to mind, rather than they don't mind, leaves open the possibility that they might.

Mum thereby takes a position that, while accepting the 'complainable' character of the circumstance (ie. the imposition on those who take her friend home), does not join with complaining about Mum's friend's conduct. In this respect, she is not aligning with the 
explicitness of the complaint which Lesley (who remember is the recipient of the complainable account) constructs. Mum demurs at overtly complaining about the matter.

A similar resistance to overtly complaining is also apparent in the sequence which follows that.

[From \#6]

37 Les: .tch uh Don' take you home though do they.

38 Mum: eh heh huh

$39 \quad$ (.)

40 Mum: We-:ll?

41 Les: $\quad$.t.hhhhh

42 Mum: $\quad$ They would if I: p-if I:-: press[ed for it?

43 Les:

44 Les:

45 Mum: $\quad$ B't I do:n't. Huh hm:.

$46 \quad(0.4)$

47 Les: hAh:

48 Mum: $\quad$ Actually the pers'n 't use t'take me:

Lesley now formulates a complaint even more explicitly on Mum's behalf. This is constructed argumentatively, with the contrastive though towards the end of the complaint (post-positioned) in line 37. So whilst being produced on Mum's behalf, Lesley's turn is designed as responsive to but rejecting, or contesting, Mum's prior qualified acceptance of the complainable, but not the complaint, they don't seem to mind. By building her turn argumentatively in this way, Lesley treats Mum’s prior turn in line 36 as having not agreed or aligned with her.

Again, Mum's response to this complaint, made more explicitly on her (Mum’s) behalf, is a qualified acceptance of the point Lesley is making, that they don't take you home, whilst not affiliating with - not joining, collaborating in, elaborating - the complaint. Mum's well-prefaced (line 41) 'explanation' that they would take her if she pressed for it declines to go along with the explicit complaint which Lesley has formulated. Mum brings this sequence to a close with a 
change of topic in line 49, exhibiting the kind of disjunctive terminations that are characteristic of disaffiliative sequences. ${ }^{\text {ix }}$

By making explicit, as complaints, matters which Mum might have been implying, Lesley has escalated the complaining by bringing to the interactional surface what was embedded in Mum's accounts, but which she was content to leave implicit. In other words, in her account of her friend not coming to tea, it appears that Mum is doing a kind of embedded complaining; but in not affiliating with Lesley's complaints (the latter explicitly on her, Mum's, behalf), Mum resists going along with the exposed complaining - with bringing to the interactional surface what Mum apparently preferred to leave implicit (our account here of 'embedded' and 'exposed' draws directly on these concepts in relation to repair; see Jefferson 1987). As with previous cases shown above, the erstwhile recipient has taken her cocomplaining, designed to be affiliative, to a place where the initial 'complainant' will not follow; the recipient has 'gone too far'. Hence they are now misaligned. So that such sequences end paradoxically with the (would-be or initial) complainant not affiliating with recipients who have joined enthusiastically in their affiliation with complainant. However, whilst they do not affiliate with their recipients, complainants do not disaffiliate from them; that is, they imply that they do not share the recipients' position (eg. by not responding, through qualified acceptances) rather than making that very overt.

In showing that, and how, Mum does not 'go along with' Lesley’s explicit complaint here, we have depicted them as misaligned at certain points, and shown that Mum does not affiliate with Lesley's complaint on her (Mum's) behalf. Because they are so closely intertwined, it might perhaps be worth adding a note about our use of these terms. It is difficult to provide precise definitions of each, but what we mean by each term is pretty close to the distinction 
which Stivers has drawn between the structural character of alignment and the evaluative character of affiliation (our terms, not hers: see Stivers forthcoming). In the context of a study of recipients' responses during the telling of stories, Stivers says that "When a recipient aligns with a telling, he/she supports the structural asymmetry of the story telling activity: that a story telling is in progress and the teller has the floor until story completion...Thus alignment is with respect to the activity in progress. ...In contrast to alignment, with the term affiliation, I mean that the hearer displays support of and endorses the teller's conveyed stance ...taking a stance that matches the teller's stance towards the event(s) being described as, for example, funny, sad, horrible, or exciting. However, aligned responses are not necessarily affiliative” (Stivers forthcoming, 6-8 of ms.). So in brief, being aligned with one another is something like going along the same track, in the same direction, without (necessarily) committing to any evaluation of what lies along that track: affiliation is very much a matter of agreeing with and supporting the other's evaluation (or in Stivers's term, stance) as he/she proceeds in that direction. In the cases we have reviewed here, in which one (the putative complainant) treats the other (the 'recipient') as having gone too far, the co-participants diverge - come to be misaligned - when one does not follow the direction in which the other is going. In (not) doing so, and in her nonaffiliative responses to the 'recipient's' explicit formulations of a complaint, the 'teller' declines to affiliate with the recipient. So that although as Stivers says, aligned responses are not necessarily affiliative, we see in these cases that non-aligned responses can withhold affiliating, and hence convey disaffiliation.

\section{Conclusion}


We have shown that in some respects affiliating and disaffiliating with complaining are two sides of the same coin. That is, the sequential conditions out of which one speaker comes to disaffiliate with the other's complaining, in response to a complaint made on behalf of that other, arise precisely from the way in which complainings are systematically launched or embarked on cautiously. Rather than being an 'initial' action unconnected to any prior talk or sequence, complaining is launched through a series of moves in which a complainable matter may first be alluded to and subsequently topicalised, in such a way as to involve the recipient in co-producing the complaint. Indeed the complainant (the one who indirectly or implicitly launches the complaining) may not overtly complain until the recipient has first done so; the 'complainant' has thereby managed the sequence so as to secure the recipient's collaboration in the complaining, and in that way the recipient's affiliation with their complaint. Thus one finding we are reporting here is that complaints are managed, interactionally and sequentially, to have recipients begin to align and affiliate with complainant, before the complaint is made explicitly.

The seeds of a complaint sequence are the first mentioning of something potentially critical, or a misfortune, problem, transgression, untoward event, etc., that is subsequently topicalised, as in examples 2, 4 and 6. In topicalising a complainable matter that was (found to be) adumbrated in the 'first mention', recipients affiliate with their co-participants: however they do so, eg. by confirming and sharing similar experiences (about the complainee, her conduct etc.) or by empathising with the other, recipients are taking the same position about the matter which they understand the other to be taking. In aligning with them about the complainability of the misfortune etc., recipients affiliate by joining with their co-participants and putative complainants, by first making more explicit and then co-producing the complaint. The practice of making what is taken to be the complainable matter more explicit is associated with escalating 
- producing more overt and stronger formulations, or more overtly critical formulations, of someone's (complainee's) conduct (wrongdoing).

That much appears to be a systematic feature of the management of complainings in conversations. We are further reporting a more episodic finding, which is a corollary of the way in which recipients may be drawn into co-constructing a complaint about a 'misfortune' (or similar event etc.). As a consequence of the way they may be drawn into aligning and affiliating with a speaker by co-constructing a complaint out of the expression of some incipiently complainable misfortune or the like, a recipient may on occasion escalate matters by making a complaint explicit - in response to which the speaker/teller/'complainant' pulls back from the position which recipient has taken. That is, in circumstances in which co-participants are aligned concerning the trouble or difficulty being specifically a complainable matter - that is, some complainee's fault etc. - recipient's collaboration in the complaining by more overtly formulating the complaint and so on is affiliative. However, in instances such as \#s 4 and 6, it can happen that they are not aligned concerning whether the misfortune, difficulty etc. is a complainable matter. For instance, in \#4 it appears that Lesley attributed her telephone line being cut off entirely to her mistake in not paying the bill - not to any fault or wrongdoing on the part of the phone company; whilst Mum consolidates what she regarded was a complainable matter, that being the phone company's service. In doing so, Mum designs her overt formulations of the complaint to affiliate with what she takes to have been the incipient complaint in Lesley's report; it turns out instead that Lesley was not launching a complaint about the phone company - she does not affiliate with Mum’s overt complaint formulation. Similarly in \#6 Lesley overtly formulates a complaint about Mum's friend (or the friend's friends), as it were on Mum's behalf, affiliating with what she takes to be the incipiently complainable matter to which Mum alludes 
when reporting that her friend will continue to go to church in the evenings because she'll be taken home. Instead Mum disaffiliates with Lesley’s affiliation; she (Mum) does not go as far as Lesley has in making a complaint overt, on the record. Hence the sequential conditions for disaffiliation are intertwined with the practices for affiliating with complaints, given that complaints are introduced or initiated cautiously, through allusions to something critical about someone, rather than as outright on-the-record criticisms and complaints. What we have reported in this paper joins two kinds of findings; first concerning the systematic emergence of complaints out of sequences in which a difficulty, trouble or misfortune alludes to an incipiently complainable matter, and in which recipients come to affiliate through collaborating in making the complaint explicit. The second finding concerns a corollary of that, illustrated in the two examples shown, which is that in some cases or episodes, by making explicit what was taken to be a complainable matter, recipients escalate the complaining, to a point at which the speaker does not affiliate with the complaint made on their behalf. 


\section{$\underline{\text { References }}$}

Dersley, Ian, and Wootton, Anthony, (2000) Complaint sequences within antagonistic argument. Research on Language and Social Interaction, 33: 375-406.

Drew, Paul, (1997) 'Open' class of repair initiators as responses to sequential sources of troubles in conversation. Journal of Pragmatics, 28: 69-101.

Drew, Paul, (1988) Complaints about transgressions and misconduct. Research on Language and Social Interaction, 31: 295-325.

Drew, Paul, and Chilton, Kathy, (2000) Calling to keep in touch: regular and habitualised telephone calls as an environment for small talk. In Coupland,Justine (ed.) Small-talk, Longman: 137-162.

Drew, Paul and Holt, Elizabeth, (1988) Complainable matters: the use of idiomatic expressions in making complaints. Social Problems, 35: 398-417.

Drew, Paul and Holt, Elizabeth, (1998) Figures of speech: Idiomatic expressions and the management of topic transition in conversation. Language in Society, 27, 495-523. 
Edwards, Derek, (Forthcoming) Moaning, whinging and laughing: the subjective side of complaints. Discourse Studies.

Jefferson, Gail, (1987) Exposed and embedded corrections. In G. Button and J.R.E. Lee (ed.) Talk and Social Organisation. Clevedon, Multilingual Matters: 86-100.

Mandelbaum, Jenny, (1991/1992) Conversational non-co-operation: An exploration of disattended complaints. Research on Language and Social Interaction, 25: 97-138.

Ochs, Elinor \& Jacoby, Sally, "Co-construction: an introduction". Research on Language and Social Interaction. 28:171-178.

Pomerantz, Anita, (1984) Agreeing and disagreeing with assessments: some features of preferred/dispreferred turn shapes. In Atkinson, J.Maxwell and Heritage, John, (eds.) Structures of Social Action: Studies in Conversation Analysis. Cambridge, Cambridge University Press: 57101.

Sacks. Harvey, (1987) On the preferences for agreement and contiguity in sequences in conversation. In Button, Graham, and Lee, John, (Eds.) Talk and Social Organization. Clevedon, Multilingual Matters: 54-69.

Sacks, Harvey, (1992) Lectures on Conversation: Volume II. Edited by Gail Jefferson, with an Introduction by Emanuel .A.Schegloff). Oxford, Blackwell. 
Schegloff, Emanuel A. (1988) On an actual virtual servo-mechanism for guessing bad news: a single case conjecture. Social Problems 35(4): 442-457

Schegloff, Emanuel A. (2005) On complainability. Social Problems, 52: 449-476.

Schegloff, Emanuel A. (2006) Sequence Organization in Interaction: A Primer in Conversation Analysis I. Cambridge, Cambridge University Press.

Stivers, Tanya, (forthcoming) Stance, alignment and affiliation during story telling: when nodding is a token of affiliation. Research on Language and Social Interaction.

${ }^{\mathrm{i}}$ This research on Affiliation and disaffiliation in interaction: language and social cohesion has been funded by the ESRC (grant number RES-000-23-0035), whose support we gratefully acknowledge. Our project was part of a six-nation collaboration formed in response to an ESF initiative in the social sciences; we are grateful to Anna Lindstrom for co-ordinating this programme.

We are particularly grateful to Gail Jefferson, for her detailed comments on the much longer report of which the present paper is a part, and for her suggestions which have helped shape this paper. 
ii For more on adjacency pairs, see for example Sacks 1992: 521-541 and elsewhere; Heritage 1984, Schegloff 2006.

iii On the use of figurative expressions - 'ticking over' meaning 'idling', not putting any effort of drive (to complete the motor metaphors) into work - in complaint sequences, especially drawing them to a close, and their role in agreement/affiliation, see Drew and Holt 1988 and Drew and Holt 1998.

${ }^{\text {iv }}$ Comic Relief is a charity event in the UK, really a series of events, focusing on one day each year when TV shows, for instance, all have some comic theme and are aimed at raising money for charities (mostly children's charities) through viewer donations. The focal day for these events in known as Red Nose Day, when children are encouraged to wear red noses to school, and there's lots of boisterous fun.

v In a much larger collection, which Gail Jefferson assembled, of over 200 'dis-ings’ (disagreements, discord, complainings, disputes etc.), every case of what came to be an explicit expression of disagreement etc. was found to be incipient in the prior talk. Even the handful of cases (about 5) which seemed to be 'initial actions', turned out, on closer inspection, to be adumbrated in the talk leading up to the overt disagreement, dispute or whatever. In the weeklong workshop (organised at the Meiji Gakunin University, Tokyo, by Aug Nishizaka) in which 
we worked on this collection, we began to formulate the hypothesis that such actions as complainings, disagreements and other such dis-ings' are never 'initial' actions in a sequence.

${ }^{\text {vi }}$ Her unenthusiastic response is No no, which by virtue of the repetition is only just a little more than a minimal agreement with Mum. It will be noticed in example 4 that Leslie continues after that (almost) minimal response, with what seems a disagreement or non-alignment with Mum:

Mum: hI’ve never had any service from them. Never.

Les: $\quad$ No:. №:.

(.)

Les: $\quad$ Oh $\underline{I}$ haa (.) we ha:ve,...

Mum complains that BT charge a certain amount for service, but that she’s never had any service from them, In contrast, almost contradiction, Lesley says that they have (had service from BT). She goes on in a playful, light-hearted tone, to say that their line is always breaking down hence the need for BT's service. In this way Lesley manages to align somewhat with Mum's complaining about BT, but without really affiliating with any of the complaints Mum makes.

vii On the matter of habitualised, regular telephone calls, eg. among family members, and some of the interactional contingencies associated with such calls, see Drew and Chilton, 2000. 
viii The example referred to here is this.

\section{Holt:2:3:5}

Ste: Ye[ah well there you are: nob'ddy has a (.) perfect life=

Les: $\quad[. \underline{\mathrm{TCH}}$ !

Ste: $=s[0$

Les: $\quad$ [ehhh heh[heh $\underline{\text { hh }}$

Ste: $\quad[. \underline{\text { tch }}$

Ste: Well he didn't either 'ee had a bad start (I mean) 'ee had iz

(0.3) .t.k.hh father shot by the Nazis 'nd iz uh .hh mother

died in: Auschvịtz ỵh kno:w [so

Les: [ㅁh really:?

The construction had his father shot by the Nazis plainly does not mean that he (Maxwell) took out a contract on his father's life. It has become a rather common grammatical construction, one which here might be generated by the immediately preceding unit, had a bad start, which might create a list-like character to Steven's illustrations of Maxwell's bad start.

ix There are a variety of ways in which a participant displays or expresses disaffiliation with his/her co-participant, ranging from the implicit (delays in responding, minimal or token agreements and the like) to the explicit (explicit expressions of disagreement). A more thorough treatment of the practices associated with disaffiliation awaits another report. 